throughout developing countries. There is a paucity of literature on the complications of medical procedures in developing countries. Most hospital infection outbreaks within underdeveloped countries generally are not reported or investigated. There is a shortage of trained personnel, records tend to be poor, and there is little incentive for this kind of investigation by hospital administrators. To our knowledge, this investigation is the first of this kind done in hospital A. It was the unusual commitment to quality care from the physician in charge and a willingness to address weaknesses in this system that made this investigation possible. Despite the difficulty in collecting this information, the information on complication rates for various procedures is crucial for appropriate decision making. Even within developed countries, patient selection for discectomy remains varied and controversial. For example, the incidence of discectomies in the United States ranges from 83 per 100,000 patients in the Western region compared to 143 per 100,000 in the South $^{9}$ versus 36 per 100,000 in Finland, ${ }^{1}$ and even within the United States rates vary markedly. Discectomies are performed twice as commonly on the West Coast compared to the East Coast. ${ }^{10}$ In Washington State, there was a 15-fold difference in rates of discectomy among different counties, ${ }^{2}$ with a significant relationship to the level of insurance reimbursements. Indications for surgery that are developed in wealthy countries should not be accepted uncritically in more resource-constrained settings where complication rates may be higher. Clearly, at hospital A, in the presence of such high complication rates, operations should be performed only if the potential benefit exceeds the high risk of discitis. At a minimum, as part of informed consent, the complication rate should be discussed explicitly with potential laminectomy patients.
It is unclear why women were more likely to develop postoperative discitis than men. Possible explanations include obesity among women that made the surgical procedure more difficult and prolonged or the surgical staff's attempt to preserve the modesty of women, resulting in a less complete skin preparation than for male patients. Because we did not observe skin preparation, nor did we have a measure of height and weight, we cannot assess whether these factors were important.

Surveillance of postoperative infections and feedback to care providers is possible even in the setting of severe resource constraints. Unless outcomes are monitored and critically considered, developing-country healthcare facilities risk wasting the scarce resources allocated to health.

\section{REFERENCES}

1. Hurve M, Alaranta H. Factors predicting the result of surgery for lumbar intervertebral disc herniation. Spine 1987;12(9):933-938.

2. Volinn E, Mayer J, Diehr P, Koevering DV, Connel FA, Loesar JD, et al. Small area analysis of surgery for low-back pain. Spine 1992;17(5):575581.

3. Kotilainen E, Valtonen S, Carlson CA. Microsurgical treatment of lumbar disc herniation: follow up of 237 patients. Acta Neurochir 1993;120:143-149.

4. Pilgrid S, Arthus N. Discitis (closed space infection) following removal of intervertebral disc. J Bone Joint Surg Am 1969;51A:713-716.

5. El-Gindi S, Aref S, Salama M, Andrew J. Infection of intervertebral disc after operation. J Bone Joint Surg Br 1976;58B:114-116.

6. Lindholm TS, Pylkkannen P. Discitis following removal of intervertebral disc. Spine 1982;7:618-620.

7. Schofferman L, Schoefferman J, Zucherman J, Ginthorpe H, Hsu K, Picetti G, et al. Occult infections causing persistent low back pain. Spine 1989;14(4):417-419.

8. Schulitz PK, Assheuer J. Discitis after procedures on the intervertebral disc. Spine 1994;19(10):1172-1177.

9. Davis $H$. Increasing rates of cervical and lumbar spine surgery in the United States, 1979-1990. Spine 1994;19(10);1117-1124.

10. Kostuik JP. Spinal surgery of the future. Presidential address, Sixth Annual Meeting of the Northern American Spine Society; Keystone, CO; July 1991. Spine 1992;17(suppl 6):S66-S70.

\title{
Directly Observed Therapy for TB
}

\section{Gina Pugliese, RN, MS Martin S. Favero, $\mathrm{PhD}$}

A panel of 11 practitioners representing the public health, behavioral, and clinical management of TB was convened by the Council on Linkages Between Academia and Public Health Practice in 1995 to develop publichealth guidelines for TB treatment completion. In addition, they evaluated evidence on the relative effectiveness of directly observed therapy in achieving treatment completion for pulmonary TB.
The panel reviewed English-language articles identified through MEDLINE (1966-August 1, 1996) with original data on directly observed therapy, supervised therapy, compliance, treatment completion, case management, and treatment adherence for TB.

The panel concluded that treatment completion rates for pulmonary TB are most likely to exceed $90 \%$, as recommended by the $\mathrm{CDC}$, when treatment is based on a patientcentered approach using directly observed therapy with multiple enablers and enhancers. Other less intensive interventions, including non- supervised strategies and modified approaches to directly observed therapy, are unlikely to achieve this recommended treatment-completion goal. Directly observed therapy also appears to be cost-effective compared with self-administered therapy, although data on cost-effectiveness are limited.

FROM: Chaulk CP, Kazandjian VA. Directly observed therapy for treatment completion of pulmonary tuberculosis: consensus statement of the Public Health Tuberculosis Guidelines Panel. JAMA 1998;279: 943-948. 